\title{
Triple-Negative Breast Cancer: Assessing the Role of Immunohistochemical Biomarkers on Neoadjuvant Treatment
}

This article was published in the following Dove Press journal: Breast Cancer: Targets and Therapy

Jesse Lopes da Silva (iD) Fabiana Resende Rodrigues $\mathbb{D}^{2}$ Guilherme Gomes de Mesquita ${ }^{2}$ Priscila Valverde Fernandes ${ }^{2}$ Luiz Claudio Santos Thuler (D) Andreia Cristina de Melo (D) ${ }^{1}$

'Division of Clinical Research and Technological Development, Brazilian National Cancer Institute (INCA), Rio de Janeiro, Brazil; ${ }^{2}$ Pathology Department, Brazilian National Cancer Institute, Rio de Janeiro, Brazil
Correspondence: Jesse Lopes da Silva Division of Clinical Research and Technological Development, Brazilian National Cancer Institute (INCA), 37 André Cavalcanti Street - 6th Floor Annex Building, Downtown, Rio de Janeiro, RJ 2023 I-050, Brazil Tel +55-2I32076585

Email jesse.silva@inca.gov.br
Objective: This study aimed to investigate the influence of immunohistochemical (IHC) biomarkers in the response to neoadjuvant chemotherapy (NACT) and survival outcomes in the subset of locally advanced triple-negative breast cancer (TNBC).

Materials and Methods: The epidermal growth factor receptor (EGFR), androgen receptor (AR), cytokeratins (CK5/6, CK14 and CK17), Ki67 and p53 immunohistochemistry were evaluated on 171 cases of TNBC submitted to NACT and subsequently to surgery. Intensity and percentage of the expression of these biomarkers were combined to formulate a specific score, that was correlated with prognostic features and assessed for survival outcomes.

Results: Most patients had advanced clinical-stage tumors (stage III: 83.6\%; cT3/T4: 85.9\%; cN1-3: 71.3\%). The predominant histological subtype was high-grade $(67.3 \%)$ and invasive ductal carcinoma (93.6\%). The residual cancer burden (RCB) 0-1 corresponded to $28.7 \%$ of cases and low-risk lymph node ratio (LNR) represented 77.2\%. High Ki67 expression only showed a significant correlation with grade 3 tumors $(\mathrm{p}=0.0157)$. CK5/6 was observed in 16\% (27/169), CK14 was positive in 10.1\% (17/169), CK17 in 91.1\% (153/ 168), p53 in 52.6\% (70/133), EGFR in 92.9\% (157/169 cases), AR in 13\% (22/169) and Ki67 index was scored $\geq 40 \%$ in $57.9 \%$ (95/165). No IHC biomarker significantly impacted response or survival. Regarding the analysis of the outcomes of event-free survival (EFS) and overall survival (OS), clinical stage $(\mathrm{p}=0.014$ and $\mathrm{p}=0.042$, respectively), RCB $(\mathrm{p}<$ 0.0001 and $\mathrm{p}<0.0001$, respectively) and $\operatorname{LNR}(\mathrm{p}<0.0001$ and $\mathrm{p}<0.0001$, respectively) showed significant association.

Conclusion: No IHC biomarker evaluated showed a significant association with a response or survival outcomes in TNBC patients. Clinical stage, LNR and RCB stood out for strongly influencing survival.

Keywords: triple-negative breast cancer, neoadjuvant chemotherapy, biomarkers, residual burden cancer, lymph node ratio

\section{Introduction}

According to data from GLOBOCAN 2018, breast cancer stands out for being the second most commonly diagnosed malignancy for the general population, reaching over $11 \%$ of all new cancer cases. Indeed, it is the leading cause of cancer-specific death in women worldwide. ${ }^{1}$ For Brazil, 66,280 new cases of breast cancer are estimated for each year in the period 2020-2022. ${ }^{2}$

Triple-negative breast cancer (TNBC) is defined by tumors that lack expression of the estrogen receptor (ER), progesterone receptor (PR) and human epidermal 
growth factor receptor 2 (HER2). ${ }^{3,4}$ This type of tumor behaves more aggressively and accounts for approximately $15 \%$ of breast cancers. ${ }^{5}$ Treatment for TNBC has been challenging and tumor heterogeneity widely pointed out as the reason for different clinical outcomes, often leading to different patterns of response to neoadjuvant treatment, as well as discrepant survival. ${ }^{6}$

Some gene expression profile (GEP) testing has been proposed for molecular characterization of TNBC subgroups. In 2011, Lehmann et $\mathrm{al}^{7}$ suggested a division of TNBCs into 7 molecular subtypes: immunomodulatory (IM), mesenchymal (M), mesenchymal stem-like (MSL), luminal androgen receptor (LAR), unstable (UNS) subtype and two basal-like subtypes (BL1 and BL2). Thereafter, the subclassification refinement was revised to regroup into 4 subtypes (BL1, BL2, M and LAR) based on a retrospective analysis of some clinical trials dataset. ${ }^{8}$ Although very promising, these assays are expensive and still inaccessible in many centers.

The GEP-based cluster analyses are intricately linked to the expression profiling of immunohistochemistry (IHC), which may represent a more accessible tool option for predicting response and survival outcomes. BL1 and BL2 subtypes usually express epidermal growth factor receptor (EGFR) and basal cytokeratins like CK5/6, CK14 and CK17. LAR usually has high androgen receptor (AR) expression. The high expression of p53 is likely to be an independent biomarker of shorter survival in some cohorts of patients with TNBC, as well as a high score of Ki67 proliferation index. ${ }^{9}$

The aim of this study was to investigate the influence of some IHC biomarkers, such as EGFR, AR, cytokeratins (CK5/6, CK14 and CK17), Ki67 and p53, in the response pattern to neoadjuvant chemotherapy (NACT) and survival outcomes in the subset of patients with locally advanced TNBC. This approach may help to obtain novel information for identifying specific high-risk subgroups in order to explore more effective treatments.

\section{Materials and Methods}

\section{Study Design and Ethical Considerations}

This is a cohort with retrospective data. The study was approved by the Ethics in Human Research Committee of the Brazilian National Cancer Institute (CEP-INCA), Rio de Janeiro, Brazil, under the number CAAE 61675516.9.0000.5274, and conducted in accordance with the Good Clinical Practice guidelines.

\section{Patient Selection}

Patients with newly diagnosed breast cancer enrolled at the Brazilian National Cancer Institute (INCA) between January 2010 and December 2014 were included if all the following criteria were met: a) women over 18 years old; b) confirmation of the histopathological diagnosis of TNBC (tumors with ER and PR score $<1 \%$, as well as HER-2 score $0 / 1+$ or $2+$ with negative FISH) by the INCA Pathology Department (DIPAT/INCA) according to the American Society of Clinical Oncology/College of American Pathologists (ASCO/CAP) guidelines; ${ }^{3,4} \mathrm{c}$ ) stage IIb-IIIc by the 7th American Joint Committee on Cancer - AJCC (T3-4NanyM0; TanyN1-3M0); d) submitted to NACT with anthracycline-taxane-based regimen followed by curative surgery at INCA. In its turn, patients with the second primary tumor, previously exposed to antineoplastic agents, with unresectable tumors, even when NACT was supplemented by complementary treatment with further chemotherapy and/or radiotherapy, were excluded.

\section{Neoadjuvant Regimens}

The NACT regimens were defined primarily as FAC-T (fluorouracil $500 \mathrm{mg} / \mathrm{m} 2$, doxorubicin $50 \mathrm{mg} / \mathrm{m} 2$ and cyclophosphamide $500 \mathrm{mg} / \mathrm{m} 2$, every 21 days for 3 cycles, followed by docetaxel $100 \mathrm{mg} / \mathrm{m} 2$ every 21 days for 3 cycles, intravenously) or AC-T (doxorubicin $60 \mathrm{mg} / \mathrm{m} 2$ and cyclophosphamide $600 \mathrm{mg} / \mathrm{m} 2$, every 21 days for 4 cycles, followed by docetaxel $100 \mathrm{mg} / \mathrm{m} 2$ every 21 days for 4 cycles, or followed by weekly paclitaxel $80 \mathrm{mg} / \mathrm{m} 2$ for 12 consecutive weeks without interval, intravenously).

\section{Immunohistochemistry}

Due to the scarcity of material, the core biopsy samples were analyzed in their whole tissue sections for all biomarkers of IHC. As for the surgical specimen samples, the tissue microarray (TMA) analysis was performed using standard procedures on 4- $\mu \mathrm{m}$ sections in the most representative areas of greatest tumor cellularity of formalinfixed paraffin-embedded tissue specimens, and then stained for Ki67. For both specimens, the tumor cell staining was compared with that of negative and positive controls. Moreover, the slides were scored according to the percentage of positive cells versus the total cell number.

The immunostaining scores for ER, PR and HER2 were confirmed as negative according to ASCO/CAP guidelines. ${ }^{10}$ Ki67 was assessed by nuclear staining using a mouse 
monoclonal antibody (SP 6 clone, Cell Marque) at 1:500 dilution. The expression level of Ki67 was considered to be low if the percentage of nuclear staining was $<40 \%$ and high if $\geq 40 \% .{ }^{11}$ For AR (clone SP107, Cell Marque; dilution 1:50), ${ }^{12}$ CK5/6 (clone D5 \& 16B4, Cell Marque; dilution 1:100), CK14 (clone D5 \& 16B4, Cell Marque; dilution 1:1000) and CK17 (Clone EP98, Cell Marque; dilution 1:500) the cut-off value for the positive result was defined when the score was $\geq 1 \%{ }^{13}$ EGFR (clone HPA018530, Sigma; dilution 1:300) and p53 (clone SP53, Cell Marque; dilution 1:500) were considered positive when $\geq 10 \%$ of positive cells were observed. ${ }^{14}$ The representation of high and low expression of the markers are highlighted in Figure 1 . The entire analysis was performed in duplicate by two experienced pathologists at the DIPAT-INCA.

\section{Other Pathological and Clinical Variables}

Patients were identified through the internal database and the data were collected from electronic hospital records and medical charts. The following clinical and pathological variables were evaluated: age at diagnosis, ethnicity (Caucasian or others according to national institutional statistical classifications, $\mathrm{IBGE}^{15}$ ), body mass index (BMI), schooling ( $\leq 8$ years of formal education correspond to less than elementary level and $>8$ years correspond to more than elementary formal education), type of NACT (FAC-T or AC-T), clinical stage (II-III), clinical T stage (cT), clinical nodal stage (cN), residual cancer burden (RCB), histological type, Elston histological grade (1: low grade; 2: moderate grade; 3: high grade), type of surgery (radical or conservative, axillary approach). Regarding the lymph node ratio (LNR, the ratio of positive axillary lymph nodes to the total number of nodes examined), the patients were divided into low- $(\leq 0.20)$, intermediate- $(>0.20$ and $\leq 0.65)$ and high-risk $(>0.65)$ groups. ${ }^{16}$

\section{Outcomes}

The RCB score followed the standard four-level categorical variable (RCB "classes" $0,1,2$, and 3 ) ${ }^{17}$ The pathological complete response (pCR) was narrowly defined as no viable residual tumor in the breast or axilla (ypT0N0). Event-free survival (EFS) was calculated from the date of diagnosis to the earliest date of disease progression, death from any cause, or discontinuation of treatment for initiation of complementary treatment due to poor response to standard NACT. Overall survival (OS) was calculated from the date of diagnosis to death from any cause.

\section{Statistical Analysis}

Data were processed using R environment. All continuous variables were evaluated by the Shapiro-Wilk test of normality. Using the non-parametric Wilcoxon test, the value of Ki67 expression before and after NACT was correlated with response and survival outcomes. To assess the correlation of the Ki67 score with other clinical-pathological

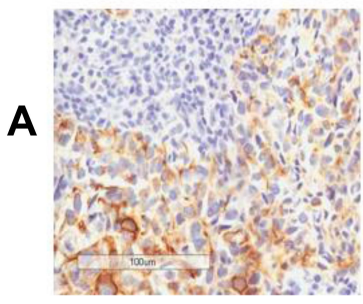

High CK 5/6

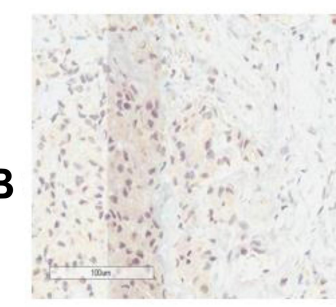

Low CK 5/6

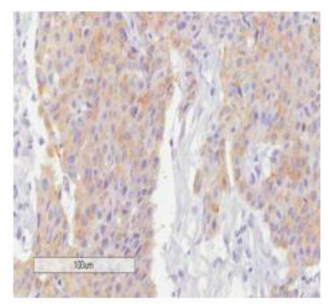

High CK 14

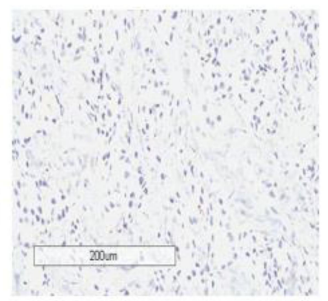

Low CK 14

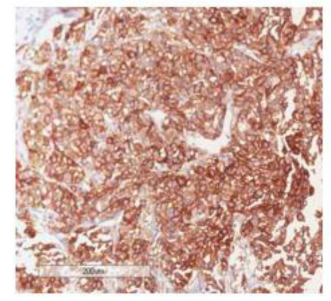

High EGFR

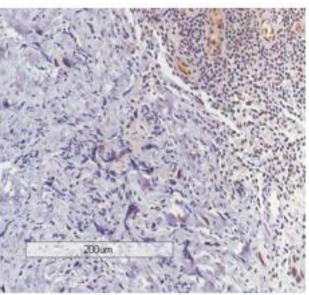

Low EGFR

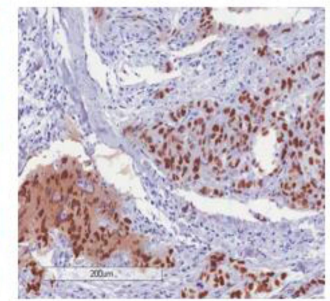

High p53

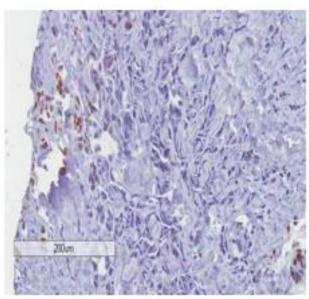

Low p53

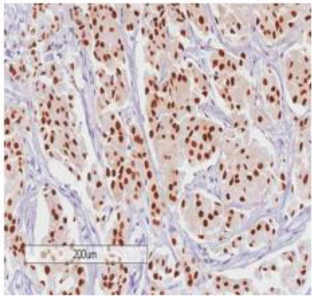

High AR

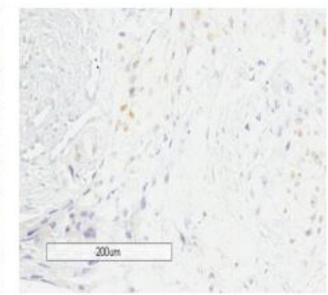

Low AR

Figure I Triple-negative breast cancer. (A) Representative images of immunohistochemical staining of high CK 5/6, CK 14, EGFR, p53 and AR. (B) Representative images of immunohistochemical staining of low CK 5/6, CK 14, EGFR, p53 and AR. Original magnification: $\times 400$ ( $\times 40$ objective). Abbreviation: AR, androgen receptor. 
variables, the Mann-Whitney $U$-test and, when necessary, the Spearman correlation test were used. For the RCB outcome, logistic regression was used for each variable assessed. Survival rates were calculated by Kaplan-Meier curves for each factor and were compared by Log-rank test. The crude Hazard Ratio (HR) for each factor was calculated by the Cox proportional hazards model. Regarding multivariate analysis, all variables with an association with survival outcomes at $\mathrm{p}$-value $<0.20$ were included and the Akaike Information Criterion was used to pick the most suitable model for multiple Cox analysis. A p-value of less than 0.05 was statistically significant. The missing data were excluded from the analysis.

\section{Results}

A total of 235 patients were included according to the study criteria. After excluding patients with essential missing data, mainly due to scarce or unavailable tumor sample, 171 cases of women with locally advanced TNBC undergoing NACT followed by curative surgery were chosen for final analysis (Figure 2). The main characteristics of the patients are summarized in Table 1. The mean age was 50.5 years (standard deviation, SD 10.7). Furthermore, most women were non-Caucasian $(53.8 \%)$ and the mean BMI was $28.5 \mathrm{~kg} / \mathrm{m} 2$ (SD 5.9).

At diagnosis, most patients had outer quadrant (57.9\%) and advanced clinical stage tumors (stage III: $83.6 \%$; cT3/ T4: $85.9 \%$; cN1-3: 71.3\%). In addition, the predominant histological subtype was high-grade $(67.3 \%)$ and invasive ductal carcinoma (93.6\%). At surgery, RCB 0-1 corresponded to $28.7 \%$ of cases and low-risk LNR represented $77.2 \%$, followed by intermediate-risk LNR (15.2\%) and low-risk LNR (7.6\%) (Table 1). Among the variables evaluated, high Ki67 expression only showed a significant correlation with grade 3 tumors $(\mathrm{p}=0.0157$ ) (data not shown).

As for the systemic neoadjuvant treatment, 68.4\% (117 cases) of the patients in the study received the AC-T
Total number of breast cancer patients enrolled at INCA between 2010-2014 ( $n=6686)$

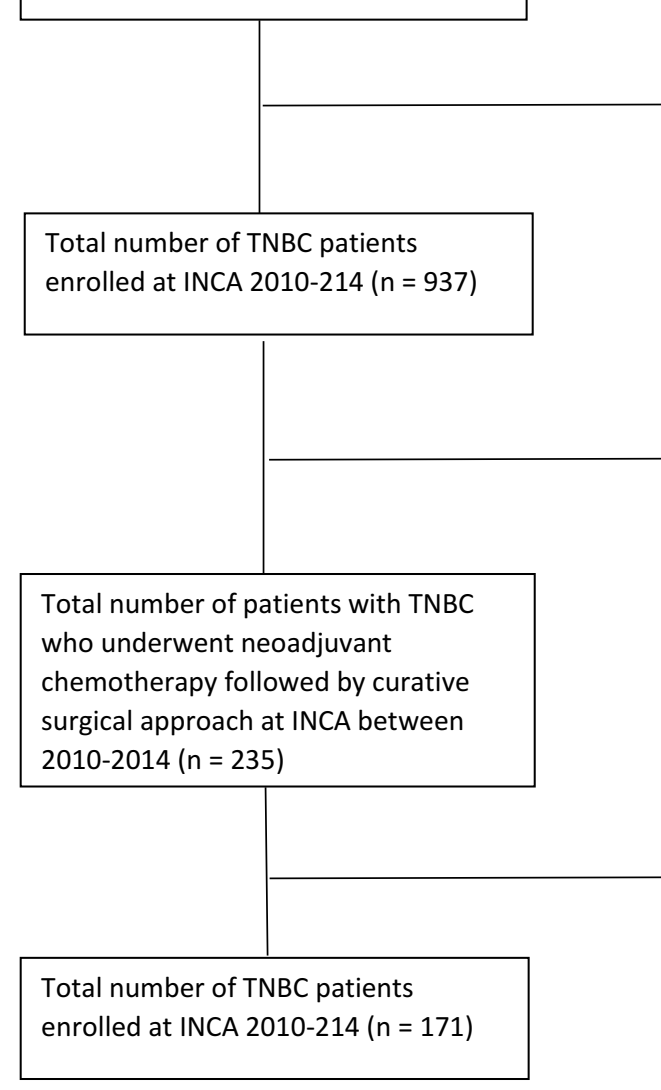

Other subtypes of breast cancer excluded: LUMINAL, HER-2, sarcoma, phyllodes tumor, lymphoma, etc. $(n=5749)$
Patients with metastatic disease, treated with primary surgery, ineligible for curative surgery after neoadjuvant treatment, poor general condition or prohibitive comorbidities for NACT. $(n=702)$
Patients with essential missing clinical data and pathological specimens. $(n=64)$

Figure 2 Study profile. 
Table I Clinicopathologic Characteristics of Patients and Treatment Data

\begin{tabular}{|c|c|}
\hline Clinical Variables & $n=|7|(100 \%)$ \\
\hline Mean age (SD) & $50.5(10.7)$ \\
\hline Race/ethnicity White & $78(46.2 \%)$ \\
\hline BMI mean Kg/m2 (SD) & $28.5(5.9)$ \\
\hline Schooling $\geq 8$ years & 90 (54.2\%) \\
\hline \multicolumn{2}{|l|}{ Clinical staging } \\
\hline Stage II & $28(16.4 \%)$ \\
\hline Stage III & 143 (83.6\%) \\
\hline cTx & $\mathrm{I}(0.6 \%)$ \\
\hline cT2 & $23(13.5 \%)$ \\
\hline cT3 & 70 (40.9\%) \\
\hline cT4 & 77 (45\%) \\
\hline cNO & 49 (28.7\%) \\
\hline cNI-N3 & 175 (7I.3\%) \\
\hline \multicolumn{2}{|l|}{ Histological grade } \\
\hline Grade I & $3(1.8 \%)$ \\
\hline Grade 2 & $53(31 \%)$ \\
\hline Grade 3 & $115(67.3 \%)$ \\
\hline \multicolumn{2}{|l|}{ Quadrant } \\
\hline Inner & $72(42.1 \%)$ \\
\hline Outer & 99 (57.9\%) \\
\hline \multicolumn{2}{|l|}{ Histological type } \\
\hline Metaplastic & II (6.4\%) \\
\hline Non-special type invasive carcinoma & $160(93.6 \%)$ \\
\hline \multicolumn{2}{|l|}{ NACT regimen } \\
\hline AC-T & 117 (68.4\%) \\
\hline FAC-T & $54(31.6 \%)$ \\
\hline Time from diagnosis to NACT mean (SD) & $104.9(93.1)$ \\
\hline Complete NACT treatment & $149(87.1 \%)$ \\
\hline \multicolumn{2}{|l|}{ Type of surgery } \\
\hline Breast conserving surgery & $6(3.5 \%)$ \\
\hline Mastectomy & 165 (96.5\%) \\
\hline \multicolumn{2}{|l|}{ Axillary approach } \\
\hline Sentinel lymph node biopsy & $10(5.8 \%)$ \\
\hline Axillary lymph node dissection & $145(86 \%)$ \\
\hline Unknown & $16(8.2 \%)$ \\
\hline \multicolumn{2}{|l|}{$\mathrm{RCB}$} \\
\hline 0 & $36(21.1 \%)$ \\
\hline I & $13(7.6 \%)$ \\
\hline 2 & $74(43.3 \%)$ \\
\hline 3 & $48(28.1 \%)$ \\
\hline \multicolumn{2}{|l|}{ LNR } \\
\hline Low risk $(\leq 0.20)$ & $132(77.2 \%)$ \\
\hline Intermediate risk $(0.20-0.65)$ & $26(15.2 \%)$ \\
\hline High risk $(>0.65)$ & $13(7.6 \%)$ \\
\hline
\end{tabular}

Abbreviations: SD, standard deviation; BMI, body mass index; NACT, neoadjuvan chemotherapy; AC-T, doxorubicin/cyclophosphamide followed by taxane; FAC-T, doxorubicin/cyclophosphamide/fluorouracil followed by taxane; RCB, residual cancer burden; LNR, lymph node ratio. regimen and $87.1 \%$ (149 cases) completed the treatment. The average time from diagnosis to the start of NACT was 104.9 days (SD 93.1). The vast majority of patients underwent radical surgery (165 cases, $96.5 \%$ ) and axillary dissection (145 cases, $86 \%$ ) (Table 1).

As shown in Table 2, the positive expression of CK $5 / 6$ was observed in $16 \%$ (27 cases) of the total number of tested cases (169 cases). CK14 was positive in $10.1 \%$ (17 cases) of 169 cases. CK17 positive occurred in 91.1\% (153 cases) of 168 cases tested. The p53 positivity was seen in $52.6 \%$ ( 70 out of 133 cases tested). EGFR was positive in $92.9 \%$ (157 cases) of the total number of tested cases (169 cases). AR was positive in 13\% (22 cases) of 169 cases tested. And for the Ki67 index, 57.9\% (95 cases) of core biopsy samples showed high expression, with a median of $40 \%$ (interquartile range, IR 55).

As for the outcome of RCB, clinical stage II was the only characteristic that significantly showed an association with the greater response $(\mathrm{p}=0.026)$. The other variables and biomarkers did not show any association with the outcome of RCB, as highlighted in Table 2 . Following the Akaike information criterion, the multivariate analysis of the final model chosen was formed by $\mathrm{p} 53(\mathrm{p}=0.063)$ and clinical stage $(\mathrm{p}=0.032)$ (data not shown). In patients with residual disease, the variation in Ki67 expression pre- and post-NACT was not statistically significant in those who presented RCB1/2 versus RCB 3 (Figure 3).

The univariate analysis of clinical-pathological variables and biomarkers for risk of recurrence and risk of death is presented in detail in Table 3. With a median follow-up of 62.5 months (95\% Confidence Interval, 95\% CI 60.2-67.9), and considering that there were 83 events of death or recurrence, the estimate of patients alive without recurrence in 60 months was $57.42 \%$ (95\% CI 50.11-65.78). As highlighted in Figures 4 and 5, regarding the analysis of variables and biomarkers for the outcomes of EFS and OS, by using the Log rank testing and KaplanMeier analysis, clinical stage $(p=0.014$ and $p=0.042$, respectively), RCB ( $p<0.0001$ and $\mathrm{p}<0.0001$, respectively) and LNR ( $<<0.0001$ and $p<0.0001$, respectively) showed a significant association. The collinearity effect of the variables RCB, LNR and clinical stage observed in this cohort, as well as the negative results of immunohistochemical markers, hindered the multivariate analysis for EFS and OS. 
Table 2 Correlation of Expression Profile of Biomarkers and Clinical-Pathological Characteristics with Residual Burden Cancer by Logistic Regression Through Univariate Analysis

\begin{tabular}{|c|c|c|c|}
\hline Variables/Biomarkers & RCB $2 / 3$ & RCB 0/I & Crude p-value \\
\hline & $\mid 22$ (7|.4\%) & 49 (28.7\%) & \\
\hline Age mean (SD) & $50.4(10.4)$ & $50.7(12.2)$ & 0.849 \\
\hline Ki67 & & & 0.127 \\
\hline Low expression & $54(78.3 \%)$ & $15(21.7 \%)$ & \\
\hline High expression & $64(67.4 \%)$ & 31 (32.6\%) & \\
\hline CK5/6 & & & 0.701 \\
\hline Negative & $100(70.4 \%)$ & $42(29.6 \%)$ & \\
\hline Positive & 20 (74.1\%) & 7 (25.9\%) & \\
\hline CKI4 & & & 0.547 \\
\hline Negative & 109 (71.7\%) & $43(28.3 \%)$ & \\
\hline Positive & II (64.7\%) & $6(35.3 \%)$ & \\
\hline CKI7 & & & 0.337 \\
\hline Negative & $9(60 \%)$ & $6(40 \%)$ & \\
\hline Positive & 110 (71.9\%) & $43(28.1 \%)$ & \\
\hline p53 & & & 0.057 \\
\hline Negative & 50 (79.4\%) & $13(20.6 \%)$ & \\
\hline Positive & 45 (64.3\%) & $25(35.7 \%)$ & \\
\hline EGFR & & & 0.136 \\
\hline Negative & II (91.7\%) & I (8.3\%) & \\
\hline Positive & $109(69.4 \%)$ & 48 (30.6\%) & \\
\hline Androgen receptor & & & 0.754 \\
\hline Negative & 105 (7I.4\%) & $42(28.6 \%)$ & \\
\hline Positive & 15 (68.2\%) & 7 (3I.8\%) & \\
\hline Quadrant & & & 0.215 \\
\hline Inner & $55(76.4 \%)$ & $17(23.6 \%)$ & \\
\hline Outer & $67(67.7 \%)$ & $32(32.3 \%)$ & \\
\hline Clinical stage & & & 0.026 \\
\hline II & $15(53.6 \%)$ & $13(46.4 \%)$ & \\
\hline III & 107 (74.8\%) & $36(25.2 \%)$ & \\
\hline NACT regimen & & & 0.863 \\
\hline AC-T & 83 (70.9\%) & $34(29.1 \%)$ & \\
\hline FAC-T & 39 (72.2\%) & I5 (27.8\%) & \\
\hline Histological type & & & 0.433 \\
\hline Non-special type IDC & 113 (70.6\%) & 47 (29.4\%) & \\
\hline Metaplastic & 9 (78I.8\%) & $2(18.2 \%)$ & \\
\hline \multicolumn{4}{|l|}{ Grade } \\
\hline I & $2(66.7 \%)$ & I (33.3\%) & \\
\hline 2 & $36(67.9 \%)$ & 17 (32.1\%) & 0.964 \\
\hline 3 & $84(73 \%)$ & 31 (27\%) & 0.807 \\
\hline
\end{tabular}

Note: Statistically significant results are in bold.

Abbreviations: RCB, residual cancer burden; SD, standard deviation; NACT, neoadjuvant chemotherapy; AC-T, doxorubicin/cyclophosphamide followed by taxane; FAC-T, doxorubicin/cyclophosphamide/fluorouracil; IDC, invasive ductal carcinoma. 


\section{Discussion}

To date, this is one of the largest series in this subset of TNBC performed with Brazilian women. A thorough evaluation of clinical-pathological features and IHC biomarkers was carried out. INCA is the largest public tertiary cancer referral center in Brazil, and TNBCs account for approximately $14 \%$ (unpublished data) of all breast cancers enrolled at the institute, which is lower than the rates in other Western population. The results of this study suggested that there is no association of the IHC biomarkers tested with either response or survival outcomes. In contrast, it was shown that clinical stage III, RCB $\geq 2$ and LNR $>0.65$ were associated with poorer survival outcomes.

The median age of 50.1 years is in line with those of other series already published, corroborating the idea that TNBC is likely to occur in younger women. ${ }^{18}$ Other ominous features that also prevailed in the current study were high-grade tumors and locally advanced disease at diagnosis with axillary nodal involvement, which somehow explains the fact that almost all patients underwent radical surgery. ${ }^{19}$ The mean time from diagnosis to treatment onset was quite long, over 100 days. Although not shown to be associated with survival outcomes in this cohort, it is highly suspected that delays in NACT onset can decrease the response rate and shorten survival.
In virtually all types of breast cancer, the higher expression of Ki67 has been associated with better response and increased risk of relapse to neoadjuvant chemotherapy. Based on a meta-analysis of 35 studies with 7716 patients enrolled, ${ }^{11}$ a high Ki-67 expression $\geq 40 \%$ was strongly defined as a poor prognostic factor in resected TNBC, being associated with a greater risk of recurrence and death compared with lower expression rates. In the current cohort, more than half of the patients had Ki67 $\geq 40 \%$, which is in accordance with previous studies. $^{20,21}$ In contrast to another series, ${ }^{22}$ the Ki67 expression, as well as reduction of Ki67 expression more than $20 \%$ after NCT, was not associated with response rate or death.

Based on immunohistochemical staining for markers as CK5/6, CK14, CK17 and/or EGFR, basal-like breast cancer may be defined as a subset of the positive tumor for one or all the four markers. ${ }^{23}$ Defined as an aggressive molecular subtype by the current classification proposed by Lehmann et $\mathrm{al}^{8}{ }^{8}$ the survival outcomes for these tumors are likely to be poorer, although a higher pCR rate (41\%) has been observed, suggesting greater chemosensitivity. Moreover, they are tumors that appear to be associated with higher histological grade, higher mitotic index and lower differentiation, and it is postulated that this is due to higher neovascularization level caused by vascular
A

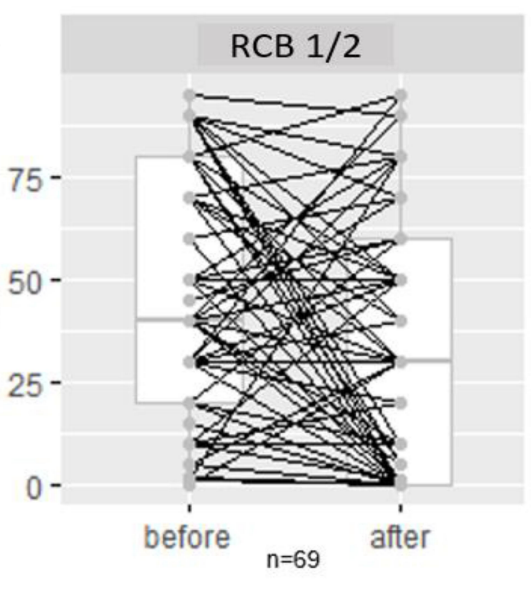

10 (IR 50)

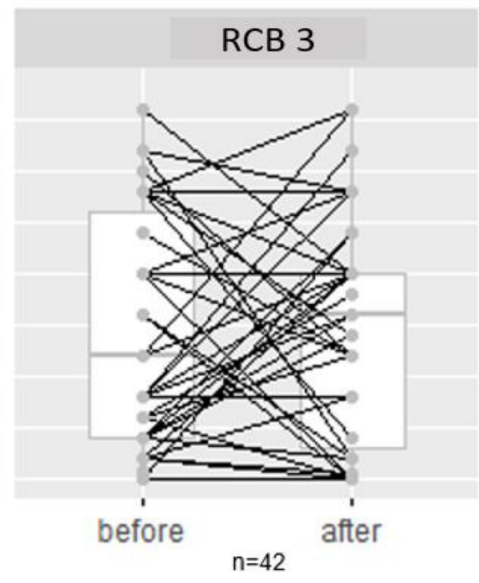

0 (IR 48.8)

$\mathrm{p}=\mathbf{0 . 3 6 2 9}$

Mann-Whitney test

B
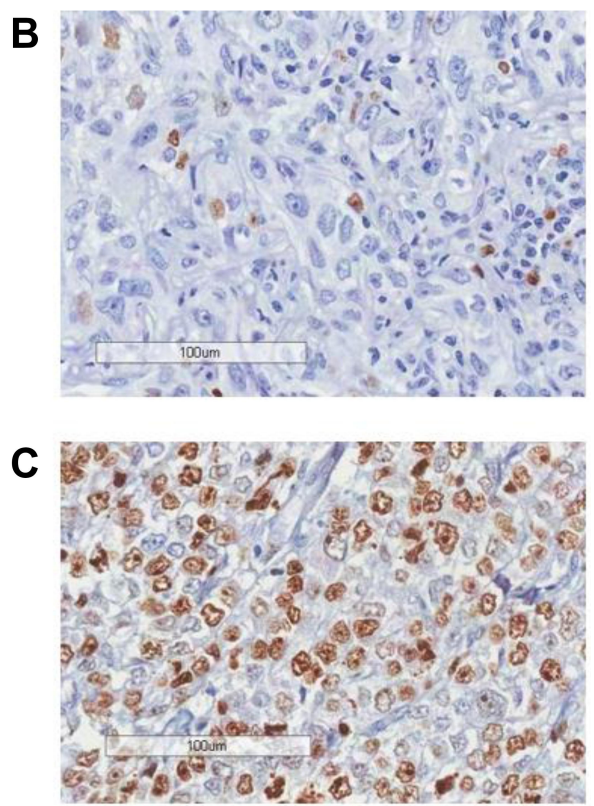

Figure 3 (A) The correlation between change in Ki67 value and RCB status in patients with residual disease. In such cases, the median absolute Ki67 reductions were $10 \%$ and $0 \%$ in patients with good response (RCBI/2) and poor response (RCB 3), respectively. (B) Immunohistochemical Ki67 staining in TNBC, representative image of Ki67 with low expression (magnification, x 200). (C) Representative image of Ki67 with high expression (magnification, x 200). Abbreviations: IR, interquartile range; RCB, residual cancer burden; TNBC, triple-negative breast cancer. 
Table 3 Univariate Analysis According to Survival Outcome

\begin{tabular}{|c|c|c|}
\hline Variables/Biomarkers & Crude HR for EFS (95\% Cl, p-value) & Crude HR for OS ( $95 \% \mathrm{Cl}$, p-value) \\
\hline \multicolumn{3}{|l|}{ Clinical stage } \\
\hline \multicolumn{3}{|l|}{$\mathrm{II}^{*}$} \\
\hline III & $2.56(1.18-5.57, p=0.017)$ & $2.20(1.01-4.79, p=0.047)$ \\
\hline \multicolumn{3}{|l|}{$\mathrm{RCB}$} \\
\hline \multicolumn{3}{|l|}{$2 / 3^{*}$} \\
\hline $0 / 1$ & $0.20(0.10-0.4 \mathrm{I}, \mathrm{p}<0.00 \mathrm{I})$ & $0.15(0.07-0.35, \mathrm{p}<0.00 \mathrm{I})$ \\
\hline \multicolumn{3}{|l|}{ LNR } \\
\hline \multicolumn{3}{|l|}{ Low risk* } \\
\hline Intermediate risk & $2.86(I .7 I-4.78, p<0.00 I)$ & $2.73(1.59-4.69, p<0.001)$ \\
\hline High risk & $7.98(4.14-15.38, p<0.001)$ & $5.43(2.8 I-10.47, p<0.00 I)$ \\
\hline \multicolumn{3}{|l|}{ NACT regimen } \\
\hline \multicolumn{3}{|l|}{ AC-T* } \\
\hline FAC-T & $1.35(0.86-2.11, p=0.188)$ & $1.35(0.85-2.15, p=0.203)$ \\
\hline \multicolumn{3}{|l|}{ CKI4 } \\
\hline \multicolumn{3}{|l|}{ Negative* } \\
\hline Positive & $1.07(0.53-2.14, p=0.852)$ & $0.92(0.42-2.0 \mathrm{I}, \mathrm{p}=0.836)$ \\
\hline \multicolumn{3}{|l|}{ CKI7 } \\
\hline \multicolumn{3}{|l|}{ Negative* } \\
\hline Positive & $1.06(0.49-2.30, p=0.884)$ & $0.92(0.42-2.01, p=0.838)$ \\
\hline \multicolumn{3}{|l|}{ CK5/6 } \\
\hline \multicolumn{3}{|l|}{ Negative* } \\
\hline Positive & $1.22(0.69-2.18, p=0.494)$ & $1.26(0.69-2.30, p=0.45 \mathrm{I})$ \\
\hline Pre-NACT Ki67 mean & $1.00(0.99-1.01, p=0.589)$ & $1.00(0.99-1.00, p=0.218)$ \\
\hline \multicolumn{3}{|l|}{ Residual tumors } \\
\hline \multicolumn{3}{|l|}{$\mathrm{Ki} 67 \geq 40 \% *$} \\
\hline Ki67 $<40 \%$ & $0.82(0.5 \mathrm{I}-1.30, \mathrm{p}=0.398)$ & $0.69(0.42-1.13, p=0.141)$ \\
\hline \multicolumn{3}{|l|}{ Ki67 reduction } \\
\hline \multicolumn{3}{|l|}{$\leq 20 \% *$} \\
\hline$>20 \%$ & $0.72(0.45-1.17, p=0.191)$ & $0.65(0.40-1.08, p=0.101)$ \\
\hline \multicolumn{3}{|l|}{$p 53$} \\
\hline \multicolumn{3}{|l|}{ Negative* } \\
\hline Positive & $0.91(0.55-1.5 \mathrm{I}, \mathrm{p}=0.707)$ & $1.06(0.62-1.82, p=0.827)$ \\
\hline \multicolumn{3}{|l|}{ EGFR } \\
\hline \multicolumn{3}{|l|}{ Negative* } \\
\hline Positive & $1.18(0.48-2.91, p=0.726)$ & $0.98(0.40-2.44, p=0.969)$ \\
\hline \multicolumn{3}{|l|}{ Androgen receptor } \\
\hline \multicolumn{3}{|l|}{ Negative* } \\
\hline Positive & $0.84(0.43-1.63, p=0.609)$ & $0.85(0.42-1.70, p=0.639)$ \\
\hline \multicolumn{3}{|l|}{ Quadrant } \\
\hline \multicolumn{3}{|l|}{ Inner* } \\
\hline Outer & $\mathrm{I} .3 \mathrm{I}(0.84-2.05, \mathrm{p}=0.24 \mathrm{I})$ & $1.34(0.83-2.15, p=0.227)$ \\
\hline
\end{tabular}

(Continued) 
Table 3 (Continued).

\begin{tabular}{|l|l|l|}
\hline Variables/Biomarkers & Crude HR for EFS (95\% Cl, p-value) & Crude HR for OS (95\% CI, p-value) \\
\hline $\begin{array}{c}\text { Grade } \\
\text { I }\end{array}$ & & \\
2 & $1.19(0.16-8.79, \mathrm{p}=0.865)$ & $0.72(0.10-5.35, \mathrm{p}=0.748)$ \\
3 & $1.25(0.17-9.04, \mathrm{p}=0.825)$ & $0.79(0.11-5.74, \mathrm{p}=0.817)$ \\
\hline
\end{tabular}

Notes: *Reference. Statistically significant results are in bold.

Abbreviations: RCB, residual cancer burden; LNR, lymph node ratio; NACT, neoadjuvant chemotherapy; AC-T, doxorubicin/cyclophosphamide followed by taxane; FAC-T, doxorubicin/cyclophosphamide/fluorouracil followed by taxane.

endothelial growth factor (VEGF) overexpression. Approximately $75-80 \%$ of TNBC cases are estimated to be of the basal-like breast cancer subtype. ${ }^{24}$

The expression of the cytokeratins was quite variable. Through the individual analysis of each marker in this cohort, they were not confirmed as significant to influence response or survival. The grouped analysis of the markers to correlate with Lehmann's molecular subtypes was not possible due to the asymmetric distribution of the sample as well as the lack of molecular tests. For CK5/6 (16\%) and CK14 (10.1\%), there were few patients with positive expression, while for CK17 (91.1\%) most of the patients were positive, which may suggest a different genomic profile of TNBC in the Brazilian population when compared to other populations. Probably due to technical issues, as the manual score might be impaired by the often weak and focal reactivity and intratumor heterogeneity, CK5/6 expression by IHC presents a significant variability amidst previous studies of TNBC, ranging from $24 \%$ to $72 \% .{ }^{25}$ The results of a cohort study with breast cancer patients performed by van de Rijn et $\mathrm{al}^{26}$ have suggested that expression of CK 5/6 was associated with poor clinical outcomes in node-negative breast cancers, regardless of tumor size and tumor grade. Other authors also have suggested $\mathrm{CK} 5 / 6$ as a predictive and prognostic independent marker. ${ }^{23,27,28}$
A

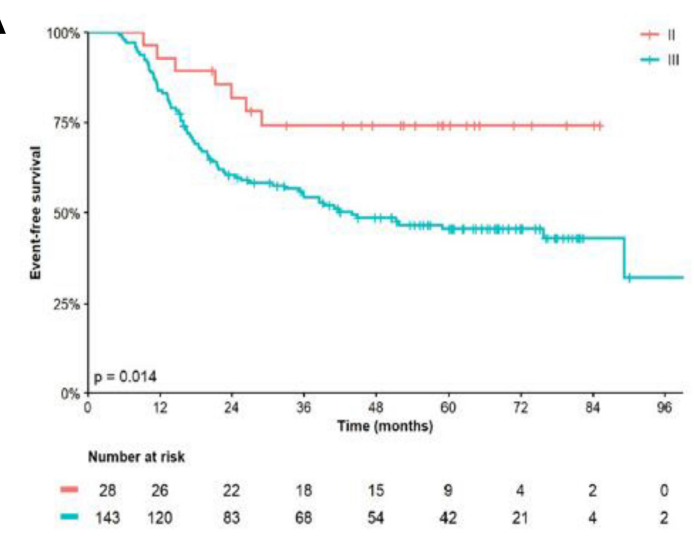

B

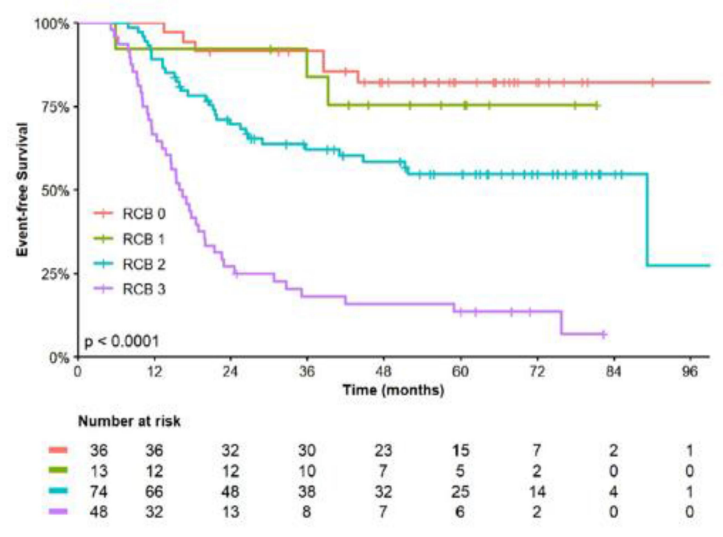

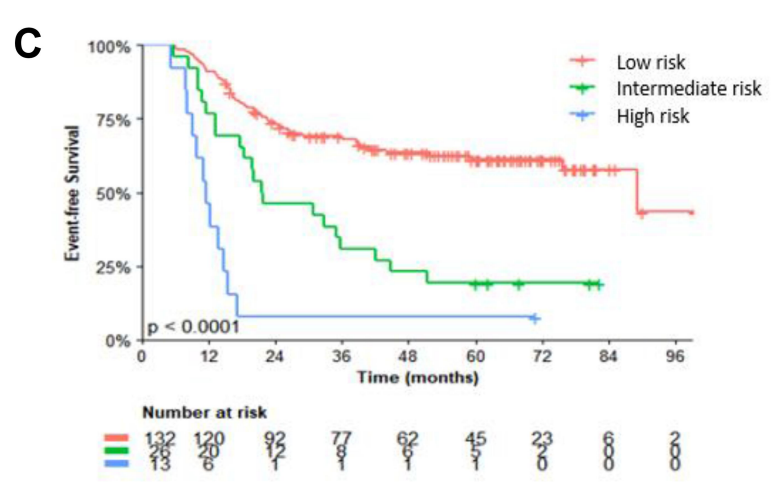

Figure 4 Kaplan-Meier event-free survival estimates according to: clinical stage (A), residual cancer burden (RCB) (B) and lymph node ratio (LNR) (C). 
A

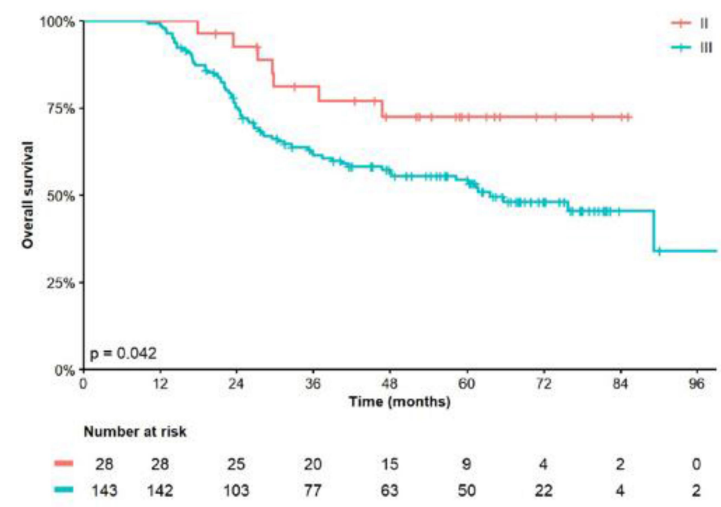

B

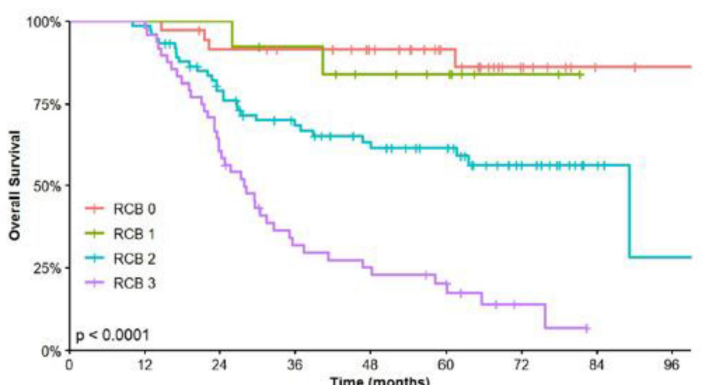

Number at risk

$\begin{array}{ccccccccc}=36 & 36 & 32 & 30 & 25 & 17 & 8 & 2 & 1 \\ =13 & 13 & 13 & 11 & 8 & 6 & 2 & 0 & 0 \\ =74 & 73 & 54 & 42 & 34 & 28 & 14 & 4 & 1 \\ =\quad 48 & 48 & 29 & 14 & 11 & 8 & 2 & 0 & 0\end{array}$

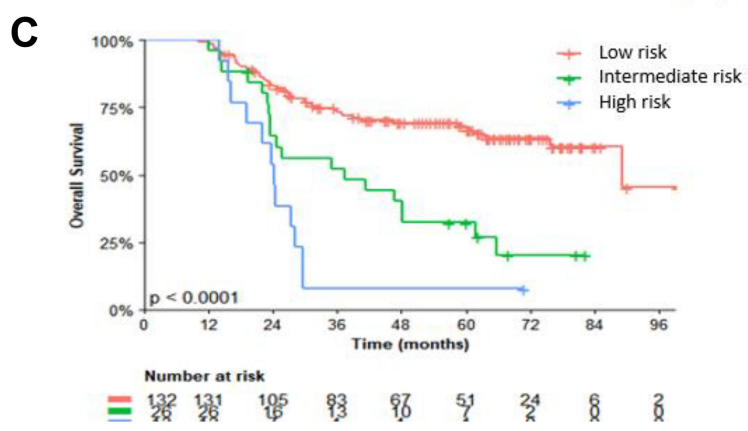

Figure 5 Kaplan-Meier overall survival estimates according to: clinical stage (A), residual cancer burden (RCB) (B) and lymph node ratio (LNR) (C).

Overall, the expression of CK14 and CK17 overlaps with CK5/6. In another Brazilian study of TNBC with less restrictive inclusion criteria, the prevalence of positive cases for CK14 was $26 \% .{ }^{29}$ In the study conducted at the Memorial Sloan-Kettering Cancer Center in patients with previously resected TNBC, CK14 positive cases corresponded to $46 \%$ of the sample and, unlike the current study, they were associated with worse disease-free survival (DFS, $\mathrm{p}=0.003,5$-year DFS 69\% vs 83\%) and OS (p $=0.01,5$-year OS $71 \%$ vs $85 \%$ ). Literature data on the prevalence of CK17 in patients with TNBC are very scarce. Some pooled analyzes with other cytokeratins have shown controversial results regarding the prognostic role of this marker. ${ }^{26,30}$

Another biomarker apparently less specific than CK5/ 6 , used to define the basal-like subtype, is the immunoreactivity to EGFR. ${ }^{7}$ The higher prevalence of patients with EGFR immunoreactivity (92.9\%) in the present study may explain the lack of association with both response and survival outcomes. There is great variability in the prevalence of EGFR overexpression in TNBC cases among studies, ranging from $13 \%$ to $78 \%$, due mainly to the lack of uniform IHC methods and to a considerable demographic variation. ${ }^{31,32}$ Some previous data showed that higher EGFR gene copy number is likely to be associated with, higher tumor grade, axillary lymph node metastasis and poorer survival. ${ }^{33}$ However, data from EGFR protein overexpression in triple-negative are controversial and apparently had no clinical relevance. ${ }^{34,35}$

With no impact on response or survival, the lower prevalence of AR in the present cohort (13\%) may represent a regional characteristic. According to previous reports, there is a considerable variability in the immunohistochemical expression of $\mathrm{AR}$ in $\mathrm{TNBC}$, ranging between $10 \%$ and $90 \% .{ }^{36-38}$ Two meta-analyses assessed the prognostic role of AR in cases with TNBC. The first assessed pooled data from 13 clinical trials that recruited 2826 patients with TNBC from 2007 to 2015. Herein, $24.4 \%$ of the cases were AR-positive, and it was associated with low tumor grade $(40.8 \%$ of patients AR-positive), and post-menopausal status (26.9\% of AR-positive patients) and lower risk of nodal involvement (28.8\% of AR-positive patients). ${ }^{39}$ In the second, with 521 TNBC patients, the odds ratio for DFS was $0.44(p=0.002){ }^{40}$ However, it is important to mention that there was no correlation of AR status with OS outcome in any of these studies.

As a predictive marker, some evidence suggests that AR-positive patients are more likely to be chemo-resistant than AR-negative patients. Analysis of 637 core biopsy 
samples from primary tumors of patients enrolled in the Gepartrio trial showed that pCR was $12.8 \%$ in AR-positive breast cancer compared to $25.4 \%$ in AR-negative ones ( $p$ $<0.0001){ }^{41}$ Similar results were observed in a Japanese retrospective cohort, in which AR-positive TNBCs presented a lower rate of $\mathrm{pCR}$ than AR-negative in a univariate analysis (HR 5.26; 95\% CI 1.39-19.86, $\mathrm{p}=0.014$ ). ${ }^{42}$

Accounting for $52.6 \%$ of the patients tested in the present study, patients with p53 expression showed no significant association with response to NACT or survival. Similarly, a large South Korean retrospective study of 11,393 TNBC patients failed to show any association of p53 with survival outcomes or response to chemotherapy.${ }^{43}$ Other studies that have shown some effect of p53 expression on response or survival to chemotherapy were limited by a small number of patients or heterogeneity. Indeed, another important limitation of these studies is that the IHC assay and the selected cutoff differ in each trial. ${ }^{44}$ ${ }^{46}$ Generally, mutant proteins are more difficult to break down, being immunohistochemically detected. Conceptually, even p53 detection does not directly represent the mutation of $\mathrm{p} 53$, data from some studies suggest this correlation. Some data from the literature suggest that p53 mutant tumors respond better to chemotherapy than p53 wild tumors and other studies suggest a negative impact of the mutation on survival. ${ }^{47-49}$

Some limitations of the current study should be highlighted. The fact that it is a single-center study, as well as its retrospective design, gives a regional trait to the analyzed population, and the results can be influenced by marked geographic differences. Intratumoral heterogeneity may have compromised some results from the TMA analysis. There were also many losses due to scarce material in a core biopsy. In addition, it was not possible to perform any molecular analysis with the available samples.

Nevertheless, some strengths of the study should be mentioned. As it is a single-center study, the same diagnostic and treatment procedures were used for all patients during the study period, strengthening the internal validity of the data. In addition, the evaluation of the samples was carried out by two experienced pathologists and the TMAs were produced with strict quality control in order to decrease the risk of false results due to intratumoral heterogeneity and technical artifacts. Another strength was the robustness of the IHC panel of biomarkers analyzed in a specific subgroup of patients with strict exclusion criteria.

\section{Conclusion}

In conclusion, pre-NACT clinical-pathological characteristics already consolidated, such as tumor size, nodal status and clinical stage, were reaffirmed in the present study as prognostic and predictive factors in TNBC. Likewise, RCB and LNR, in the context of a pathological parameter of post-NACT response, also strongly influenced survival, and can therefore be considered important and low-cost prognostic factors to direct the best adjuvant approach.

TNBC is believed to be a heterogeneous disease comprising subtypes with diverse biological behaviors and clinical outcomes. Although several IHC biomarkers have been studied as prognostic factors in non-metastatic TNBC, few studies in the specific subset of patients with locally advanced TNBC undergoing NACT were performed, with controversial results. ${ }^{50}$ Although negative, probably due to the technical limitations of a retrospective study, the data from the present cohort pave the way for further prospective studies in order to determine the real role of these factors in this scenario and correlate with expression profiling gene analyses. Lately, TNBC has been increasingly seen as a disease with intrinsic molecular and immunological heterogeneity, recognizing the variety of clinical phenotypes with diverse outcomes. Considering that NACT is insufficient in some cases, this new setting makes room for a demand for an urgent comprehensive subclassification that encompasses immune-molecular signatures to incorporate more targeted and effective treatment.

\section{Data Sharing Statement}

The datasets generated during and/or analyzed during the current study are available from the corresponding author on reasonable request.

\section{Ethical Approval}

The study was approved by the Ethics in Human Research Committee of INCA, Rio de Janeiro, Brazil, under registration number CAAE 61675516.9.0000.5274, and conducted in accordance with Good Clinical Practice guidelines.

\section{Informed Consent}

For this type of study with observational retrospective design with anonymized data analysis, the Institutional Review Board (Comitê de Ética em Pesquisa do Instituto Nacional de Câncer; CEP-INCA) decided in favor of waiving the consent form. 


\section{Acknowledgments}

The authors are indebted to all patients and their families for their trust and participation and for the provision of biological material for research purposes. The authors wish to thank Mrs. Isabele Small for technical support with statistical analysis.

\section{Author Contributions}

All authors made a significant contribution to the work reported, whether that is in the conception, study design, execution, acquisition of data, analysis and interpretation, or in all these areas; took part in drafting, revising or critically reviewing the article; gave final approval of the version to be published; have agreed on the journal to which the article has been submitted; and agree to be accountable for all aspects of the work.

\section{Funding}

This study was supported by a grant provided by AstraZeneca Brazil as a study of investigator initiative (ESR-17-12857). The sponsor approved the study design, and contributed to the decision to publish, and final approval of the manuscript.

\section{Disclosure}

Jesse Lopes da Silva and Andreia Cristina de Melo received research funding from AstraZeneca. Andreia Cristina de Melo reports grants from AstraZeneca Brazil during the conduct of the study; grants, personal fees, and non -financial support from MSD, personal fees and non-financial support from BMS, grants from AstraZeneca, Novartis, Loreal Brazil, Libbs, and Zodiac, outside the submitted work. The authors report no other conflicts of interest in this work.

\section{References}

1. Bray F, Ferlay J, Soerjomataram I, Siegel RL, Torre LA, Jemal A. Global cancer statistics 2018: GLOBOCAN estimates of incidence and mortality worldwide for 36 cancers in 185 countries. $C A$ Cancer J Clin. 2018;68(6):394-424. doi:10.3322/caac.21492

2. National Cancer Institute, Ministry of Health. Estatísticas de câncer. [Cancer Statistics]. https://www.inca.gov.br/numeros-de-cancer. Accessed July 6, 2020. Portuguese.

3. Hammond MEH, Hayes DF, Dowsett M, et al. American Society of Clinical Oncology/College of American Pathologists guideline recommendations for immunohistochemical testing of estrogen and progesterone receptors in breast cancer (unabridged version). Arch Pathol Lab Med. 2010;134(7):e48-e72. doi:10.1043/1543-2165134.7.e48
4. Wolff AC, Hammond MEH, Hicks DG, et al. Recommendations for human epidermal growth factor receptor 2 testing in breast cancer: american Society of Clinical Oncology/College of American Pathologists clinical practice guideline update. J Clin Oncol. 2013;31(31):3997-4013. doi:10.1200/JCO.2013.50.9984

5. Trivers KF, Lund MJ, Porter PL, et al. The epidemiology of triplenegative breast cancer, including race. Cancer Causes Control. 2009;20(7):1071-1082. doi:10.1007/s10552-009-9331-1

6. Chiu AM, Mitra M, Boymoushakian L, Coller HA. Integrative analysis of the inter-tumoral heterogeneity of triple-negative breast cancer. Sci Rep. 2018;8(1):1-14. doi:10.1038/s41598-018-29992-5

7. Lehmann BD, Bauer JA, Chen X, et al. Identification of human triple-negative breast cancer subtypes and preclinical models for selection of targeted therapies. J Clin Invest. 2011;121(7):27502767. doi:10.1172/JCI45014

8. Lehmann BD, Jovanović B, Chen X, et al. Refinement of triplenegative breast cancer molecular subtypes: implications for neoadjuvant chemotherapy selection. PLoS One. 2016;11(6):e0157368. doi:10.1371/journal.pone. 0157368

9. Santonja A, Sánchez-Muñoz A, Lluch A, et al. Triple negative breast cancer subtypes and pathologic complete response rate to neoadjuvant chemotherapy. Oncotarget. 2018;9(41):26406-26416. doi:10.18632/ oncotarget. 25413

10. Irvin WJ, Carey LA. What is triple-negative breast cancer? Eur J Cancer. 2008;44(18):2799-2805. doi:10.1016/j.ejca.2008.09.034

11. Wu Q, Ma G, Deng Y, et al. Prognostic value of Ki-67 in patients with resected triple-negative breast cancer: a meta-analysis. Front Oncol. 2019;9. doi:10.3389/fonc.2019.01068

12. Bhattarai S, Klimov S, Mittal K, et al. Prognostic role of androgen receptor in triple negative breast cancer: a multi-institutional study. Cancers. 2019;11(7):995. doi:10.3390/cancers 11070995

13. Peng Y, Butt YM, Chen B, Zhang X, Tang P. Update on immunohistochemical analysis in breast lesions. Arch Pathol Lab Med. 2017;141 (8):1033-1051. doi:10.5858/arpa.2016-0482-RA

14. Correlation between 553 and epidermal growth factor receptor expression in breast cancer classification. GMR | Genetics and Molecular Research | The Original by FUNPEC-RP; August 24, 2015. https:// www.geneticsmr.com/articles/4334. Accessed April 29, 2020.

15. Instituto Brasileiro de Gergrafia e Estatistica. Pesquisa das Características Étnico-Raciais da População - PCERP | 2008. [Survey of Ethnic-Racial Characteristics of the Population - PCERP | 2008 | IBGE]. https://www.ibge.gov.br/estatisticas/sociais/popula cao/9372-caracteristicas-etnico-raciais-da-populacao. $\mathrm{html} ?=\& \mathrm{t}=\mathrm{O}-$ que-e. Accessed October 15, 2020. Portuguese.

16. Quintyne KI, Woulfe B, Coffey JC, Merrigan A, Gupta RK. Lymph node ratio in sentinel lymph node biopsy era: are we losing prognostic information? Clin Breast Cancer. 2017;17(2):117-126. doi:10.1016/j.clbc.2016.07.011

17. Nahleh Z, Sivasubramaniam D, Dhaliwal S, Sundarajan V, Komrokji R. Residual cancer burden in locally advanced breast cancer: a superior tool. Curr Oncol. 2008;15(6):271-278. doi:10.3747/co.v15i6.242

18. Sajid MT, Ahmed M, Azhar M, et al. Age-related frequency of triple negative breast cancer in women. $J$ Coll Physicians Surg Pak. 2014;24(6):400-403.

19. Dent R, Trudeau M, Pritchard KI, et al. Triple-negative breast cancer: clinical features and patterns of recurrence. Clin Cancer Res. 2007;13 (15):4429-4434. doi:10.1158/1078-0432.CCR-06-3045

20. Keam B, Im S-A, Lee K-H, et al. Ki-67 can be used for further classification of triple negative breast cancer into two subtypes with different response and prognosis. Breast Cancer Res. 2011;13(2): R22. doi:10.1186/bcr2834

21. Matsubara N, Mukai H, Masumoto M, et al. Survival outcome and reduction rate of $\mathrm{Ki}-67$ between pre- and post-neoadjuvant chemotherapy in breast cancer patients with non-pCR. Breast Cancer Res Treat. 2014;147(1):95-102. doi:10.1007/s10549-014-3084-6 
22. Wang R-X, Chen S, Jin X, Shao Z-M. Value of Ki-67 expression in triple-negative breast cancer before and after neoadjuvant chemotherapy with weekly paclitaxel plus carboplatin. Sci Rep. 2016;6. doi:10.1038/srep30091.

23. Nielsen TO, Hsu FD, Jensen K, et al. Immunohistochemical and clinical characterization of the basal-like subtype of invasive breast carcinoma. Clin Cancer Res. 2004;10(16):5367-5374. doi:10.1158/ 1078-0432.CCR-04-0220

24. Badowska-Kozakiewicz AM, Budzik MP. Immunohistochemical characteristics of basal-like breast cancer. Contemp Oncol. 2016;20 (6):436-443. doi:10.5114/wo.2016.56938

25. Ryu DW, Jung MJ, Choi WS, Lee CH. Clinical significance of morphologic characteristics in triple negative breast cancer. J Korean Surg Soc. 2011;80(5):301-306. doi:10.4174/jkss.2011.80.5.301

26. van de Rijn M, Perou CM, Tibshirani R, et al. Expression of cytokeratins 17 and 5 identifies a group of breast carcinomas with poor clinical outcome. Am J Pathol. 2002;161(6):1991-1996. doi:10.1016/S0002-9440(10)64476-8

27. Abd El-Rehim DM, Pinder SE, Paish CE, et al. Expression of luminal and basal cytokeratins in human breast carcinoma. J Pathol. 2004;203(2):661-671. doi:10.1002/path.1559

28. Inanc M, Ozkan M, Karaca H, et al. Cytokeratin 5/6, c-Met expressions, and PTEN loss prognostic indicators in triple-negative breast cancer. Med Oncol Northwood Lond Engl. 2014;31(1):801. doi:10.1007/s12032-013-0801-7

29. Brot M, Soares FA, Stiepcich MMA, Cúrcio VS, Gobbi H. Basal-like breast carcinomas: clinicopathologic and evolutive profile. Rev Assoc Med Bras. 2009;55:529-534.

30. Sable M, Pai TD, Shet T, Patil A, Dhanavade S, Desai SB. Triplenegative breast cancer: a comprehensive study of clinical, histomorphological, and immunohistochemical features in Indian patients. Int J Surg Pathol. 2017;25(3):230-237. doi:10.1177/1066896916667815

31. Gluz O, Liedtke C, Gottschalk N, Pusztai L, Nitz U, Harbeck N. Triple-negative breast cancer-current status and future directions. Ann Oncol. 2009;20(12):1913-1927. doi:10.1093/annonc/mdp492

32. Gumuskaya B, Alper M, Hucumenoglu S, Altundag K, Uner A, Guler G. EGFR expression and gene copy number in triple-negative breast carcinoma. Cancer Genet Cytogenet. 2010;203(2):222-229. doi:10.1016/j.cancergencyto.2010.07.118

33. Park HS, Jang MH, Kim EJ, et al. High EGFR gene copy number predicts poor outcome in triple-negative breast cancer. Mod Pathol. 2014;27(9):1212-1222. doi:10.1038/modpathol.2013.251

34. Nakajima H, Ishikawa Y, Furuya M, et al. Protein expression, gene amplification, and mutational analysis of EGFR in triple-negative breast cancer. Breast Cancer Tokyo Jpn. 2014;21(1):66-74. doi:10.1007/s12282-012-0354-1

35. Liu D, He J, Yuan Z, et al. EGFR expression correlates with decreased disease-free survival in triple-negative breast cancer: a retrospective analysis based on a tissue microarray. Med Oncol Northwood Lond Engl. 2012;29(2):401-405. doi:10.1007/s12032-011-9827-x

36. Niemeier LA, Dabbs DJ, Beriwal S, Striebel JM, Bhargava R. Androgen receptor in breast cancer: expression in estrogen receptor-positive tumors and in estrogen receptor-negative tumors with apocrine differentiation. Mod Pathol. 2010;23(2):205-212. doi:10.1038/modpathol.2009.159
37. He J, Peng R, Yuan Z, et al. Prognostic value of androgen receptor expression in operable triple-negative breast cancer: a retrospective analysis based on a tissue microarray. Med Oncol Northwood Lond Engl. 2012;29(2):406-410. doi:10.1007/s12032-011-9832-0

38. Wang C, Pan B, Zhu H, et al. Prognostic value of androgen receptor in triple negative breast cancer: A meta-analysis. Oncotarget. 2016;7 (29):46482-46491. doi:10.18632/oncotarget.10208

39. Qu Q, Mao Y, Fei X, Shen K. The impact of androgen receptor expression on breast cancer survival: a retrospective study and meta-analysis. PLoS One. 2013;8(12):e82650. doi:10.1371/journal. pone.0082650

40. Kim Y, Jae E, Yoon M. Influence of androgen receptor expression on the survival outcomes in breast cancer: a meta-analysis. J Breast Cancer. 2015;18(2):134-142. doi:10.4048/jbc.2015.18.2.134

41. Hilborn E, Gacic J, Fornander T, Nordenskjöld B, Stål O, Jansson A. Androgen receptor expression predicts beneficial tamoxifen response in oestrogen receptor- $\alpha$-negative breast cancer. $\mathrm{Br} J$ Cancer. 2016;114(3):248-255. doi:10.1038/bjc.2015.464

42. Asano Y, Kashiwagi S, Onoda N, et al. Clinical verification of sensitivity to preoperative chemotherapy in cases of androgen receptor-expressing positive breast cancer. Br J Cancer. 2016;114(1):1420. doi:10.1038/bjc.2015.434

43. Bae SY, Nam SJ, Jung Y, et al. Differences in prognosis and efficacy of chemotherapy by p53 expression in triple-negative breast cancer. Breast Cancer Res Treat. 2018;172(2):437-444. doi:10.1007/s10549018-4928-2

44. Fernández-Cuesta L, Oakman C, Falagan-Lotsch P, et al. Prognostic and predictive value of TP53 mutations in node-positive breast cancer patients treated with anthracycline- or anthracycline/taxane-based adjuvant therapy: results from the BIG 02-98 Phase III trial. Breast Cancer Res. 2012;14(3):R70. doi:10.1186/bcr3179

45. Coates AS, Millar EK, O'Toole SA, et al. Prognostic interaction between expression of p53 and estrogen receptor in patients with node-negative breast cancer: results from IBCSG Trials VIII and IX. Breast Cancer Res. 2012;14(6):R143. doi:10.1186/bcr3348

46. Lara JF, Thor AD, Dressler LG, et al. p53 expression in node-positive breast cancer patients: results from the cancer and leukemia group B 9344 trial (159905). Clin Cancer Res. 2011;17(15):5170-5178. doi:10.1158/1078-0432.CCR-11-0484

47. Blagosklonny MV. Loss of function and p53 protein stabilization. Oncogene. 1997;15(16):1889-1893. doi:10.1038/sj.onc.1201374

48. Thor AD, Moore DH II, Edgerton SM, et al. Accumulation of p53 tumor suppressor gene protein: an independent marker of prognosis in breast cancers. J Natl Cancer Inst. 1992;84(11):845-855. doi:10.1093/jnci/84.11.845

49. Petitjean A, Achatz MIW, Borresen-Dale AL, Hainaut P, Olivier M. TP53 mutations in human cancers: functional selection and impact on cancer prognosis and outcomes. Oncogene. 2007;26(15):2157-2165. doi:10.1038/sj.onc. 1210302

50. da Silva JL, Cardoso Nunes NC, Izetti P, de Mesquita GG, de Melo AC. Triple negative breast cancer: A thorough review of biomarkers. Crit Rev Oncol Hematol. 2020;145:102855. doi:10.1016/j. critrevonc.2019.102855 


\section{Publish your work in this journal}

Breast Cancer - Targets and Therapy is an international, peer-reviewed open access journal focusing on breast cancer research, identification of therapeutic targets and the optimal use of preventative and integrated treatment interventions to achieve improved outcomes, enhanced survival and quality of life for the cancer patient.
The manuscript management system is completely online and includes a very quick and fair peer-review system, which is all easy to use. Visit http://www.dovepress.com/testimonials.php to read real quotes from published authors. 